\title{
2 Evidence for an extreme founding effect in a highly successful invasive species
}

3

4 Kateryna V. Kratzer ${ }^{1}$, Annemarie van der Marel $^{1}$, Colin Garroway ${ }^{1}$, Marta López-Darias ${ }^{2}$,

5 Stephen D. Petersen ${ }^{1,3}$, Jane M. Waterman ${ }^{1}$.

$7 \quad{ }^{1}$ Department of Biological Sciences, University of Manitoba, Winnipeg, Manitoba, Canada

$8{ }^{2}$ Instituto de Productos Naturales y Agrobiología, IPNA-CSIC, San Cristóbal de La Laguna,

9 Tenerife, Spain

$10{ }^{3}$ Conservation and Research Department, Assiniboine Park Zoo, Winnipeg, Manitoba, Canada 11 


\section{Abstract}

14 The adaptive potential of invasive species is thought to decrease during founding events due to

15 reduced genetic diversity, limiting the new population's ability to colonize novel habitats.

16 Barbary ground squirrels (Atlantoxerus getulus) were purportedly introduced as a single breeding

17 pair to the island of Fuerteventura but have expanded to over a million individuals spread across

18 the island in just over 50 years. We estimated the number of founders and measured the level of

19 genetic diversity in this population using the mitochondrial displacement loop and microsatellite

20 markers. Island samples $(n=19)$ showed no variation in the d-loop, suggesting a single founding

21 female, while Moroccan samples $(n=6)$ each had unique mitochondrial haplotypes. The

22 microsatellite data of the island population $(n=256$ individuals $)$ revealed a small effective

23 population size, low levels of heterozygosity, and high levels of inbreeding, supporting a

24 founding population size of two to three individuals. Our results suggest that A. getulus has

25 undergone an intense genetic bottleneck during their colonization of the island. They are one of

26 the few species where introduction effort does not explain invasion success, although further

27 investigation may explain how they have avoided the worst expected effects following an

28 extreme genetic bottleneck.

30 Keywords: invasive species, inbreeding, effective population size, genetic bottleneck 


\section{Introduction}

36 Extreme population bottlenecks can produce inbreeding and subsequent inbreeding depression

$37[1,2]$ because genetic drift becomes more powerful than selection in small populations. When

38 drift is strong, beneficial alleles can be lost and detrimental alleles fixed due to random chance.

39 As homozygosity increases due to drift, phenotypes associated with deleterious alleles that are

40 hidden in heterozygote states become exposed to selection, and inbreeding depression occurs [for

41 reviews, see 3,4]. The strength of drift is often not apparent from the census size of a population,

42 as not all individuals contribute equally to the next generation and population size can recover

43 from a bottleneck much faster than the population's genetic diversity. However, a population

44 experiences drift at the rate of its effective population size, which underscores the fact that even

45 large populations can continue to experience strong effects of drift and continued loss of genetic

46 diversity $[5,6]$.

In some cases, the effects of inbreeding following extreme bottlenecks are not noticeable; thus,

50 species ecology, many populations are paradoxically founded by a small number of individuals

51 with reduced genetic diversity due to the small size of the available gene pool [7-9]. The ability

52 of these species to adapt to and colonize novel environments can be jeopardized by low levels of

53 genetic diversity [10]. But a sufficiently large founder population (number of individuals or

54 genotypes) [e.g. 11, 12], or multiple introduction events, which introduce new alleles into the

55 population [e.g. 13, 14; see also 7, 15] often characterize successful invasions. Bottlenecked

56 populations that retain sufficient levels of variation may regain some genetic variability through

57 mutation $[10,16,17]$, increasing their likelihood of survival. Small founder populations without 
58 subsequent introductions should, therefore, have decreased fitness and face difficulty when

59 attempting to establish in novel environments. No successful establishment of an invasive

60 mammal from either one breeding pair or one pregnant female has been recorded; an invasive

61 population founded by either scenario would be an ideal study model for the founder effect [18].

63 Here we quantify genetic diversity and estimate the effective population size of the invasive

64 population of Barbary ground squirrels (Atlantoxerus getulus) on the island of Fuerteventura,

65 Spain. Purportedly introduced as a breeding pair from Sidi Ifni, Morocco in 1965 [19], the

66 current island population has had remarkable success in population growth (estimated one

67 million) and range expansion [20,21]. We examined the mitochondrial and nuclear diversity of

68 A. getulus to resolve any discrepancies between the two differently inherited genomes [22-24].

69 We targeted the mitochondrial displacement loop and nuclear microsatellites, as any variation in

70 this recently established population would likely be found in the most rapidly evolving areas of

71 the two genomes [25]. We expected to find a single mitochondrial haplotype, high levels of

72 inbreeding, one to four microsatellite alleles at each nuclear locus, and a small effective

73 population size on the island due to the exclusive presence of alleles from a single founding pair.

74 With this research, we intend to contribute to the general knowledge on the role of genetic

75 diversity and bottlenecks in explaining the success of biological populations.

\section{2. Methods}

78 (a) Study species, trapping locations and methods

79 We trapped A. getulus according to previously described methods in various locations on

80 Fuerteventura and Morocco [see 26-29] and stored tissue samples in 95\% ethanol. Mitochondrial 
81 d-loop sequences were obtained from 45 animals, and 256 animals were genotyped at eleven

82 microsatellite loci (see S.I. for details).

83 We tested for inbreeding and variation from Hardy-Weinberg equilibrium using the "adegenet"

84 package v.2.1.1 $[30,31]$ and the "pegas" package x.0.11 Monte Carlo exact test with 1000

85 replicates [32], respectively, in R v.3.5.1 [33]. Alleles were determined to have been introduced

86 by founders rather than mutation (i.e. "founding alleles") if they had a frequency $>0.05$ and were

87 more than one repeat unit away from a common allele [12]. We performed a principal

88 component analysis (PCA) using the "ade4" package v.1.7-13 [34] to determine whether there

89 was any genetic structure in the population. We then calculated effective population size $\left(\mathrm{N}_{\mathrm{e}}\right)$

90 using the LDNE method, assuming random mating and setting the minor allele frequency to 0.05

$91[35]$.

92

\section{3. Results}

94 (a) Mitochondrial DNA

95 We found no variation among island squirrels, whereas all six individuals from Morocco had

96 unique haplotypes and showed 16 variable nucleotide sites compared to island samples, despite

97 the limited sample size of the Moroccan source (Fig. 1, Table 1). We found four variable sites

$98(0.389 \%)$ between Fuerteventura sequences and M10, the Moroccan sequence most similar to

99 those on the island (Fig. 1).

100 (b) Nuclear DNA

101 We found no evidence of large allele dropout or scoring error due to stuttering [36]. Null alleles,

102 indicated by homozygote excess, were present at five loci that were removed from the analysis

$103[37,38]$. All remaining loci were in $\operatorname{HWE}(p>0.05)$. Each locus had between two and nine 
104 alleles $(4.36 \pm 2.11$, mean \pm SD), the number of founding alleles ranging from one to five $(2.73 \pm$

$1050.65)$. Mean observed heterozygosity $\left(\mathrm{H}_{\mathrm{O}}=0.57\right)$ was greater than expected $\left(\mathrm{H}_{\mathrm{E}}=0.55\right.$; Table 1

106 supplemental information) and the average level of inbreeding was high (Fig. 2: average $F=$

$1070.23[0.10-0.60, \min -\max ])$. Since we found no evidence of population structure (S.I. Fig. 1),

108 we assumed that our sample was representative of the entire island population. We estimated $\mathrm{N}_{\mathrm{e}}$

109 to be 77.2 (95\% CI: $56.3,109.5)$.

\section{4. Discussion}

112 We characterized segments of the mitochondrial and nuclear genomes of a highly successful

113 invasive island population of A. getulus to determine its genetic diversity and number of

114 founders. We observed low genetic diversity, evidence of inbreeding in mitochondrial and

115 nuclear DNA, and a single mitochondrial haplotype suggesting the presence of only one

116 founding female. We found variation between each mitochondrial d-loop sequence of Moroccan

117 samples despite a small sample size $(n=6)$, whereas the island population did not show variation

118 with a larger sample size $(n=19)$.

119 Microsatellite data also supported the hypothesis that this island population was founded by a

120 small number of individuals but data from marker Aget19 suggest that there may be more than

121 two founders (S. I. Table 2). Of nine alleles at this locus, five are present at a frequency greater

122 than 5\% [12], which is incongruous with the hypothesis that the island population was founded

123 by two individuals. However, two of these alleles (repeat lengths 319 and 339) have frequencies

124 just above the threshold of being counted as true founder alleles ( 0.0573 and 0.0553 ,

125 respectively; S. I. Table 2). It is possible these alleles were introduced by a founder, but the

126 potential that 319 and 339 are due to rare double mutations, genotyping error, or an early 
127 mutation that was propagated over the threshold cannot be overlooked. Another microsatellite

128 marker, Aget1, also has a high number of alleles but only two are present at high frequency (>

$1295 \%$ ). An interesting allele at this marker is repeat length 152, which is two repeat units away

130 from a founder allele and therefore does not comply with the recommended criteria [12].

131 However, it is present at low frequency (0.0108), and multiple mutations in the same location,

132 while unlikely, are not impossible [12]. Further investigation may confirm the true origin of

133 these alleles.

134 With an average inbreeding coefficient $F$ of 0.23 , the $A$. getulus population should be at a

135 survival or range expansion disadvantage $[39,40]$, as an increased probability of extinction

136 exists when $F$ values are at or just below "intermediate" levels $(0.30-0.40 ; 11,41]$. However,

137 the species has successfully established and spread across the island $[20,21]$ in a genetic paradox

138 of invasion [9]. Atlantoxerus getulus invasion success may be due to extrinsic habitat factors [22,

139 29], or other species-level [42, 43], behaviour [28], or life-history traits [44]. Alternatively,

140 inbreeding may have benefitted the population by purging deleterious founding alleles [41, 45].

141 Despite an estimated population size of one million, the effective population size was

142 approximately 77 individuals $(0.0077 \%)$, which is very low compared to other infamously

143 bottlenecked mammals. Northern elephant seals survived near extinction and experienced steady

144 population growth from about 100 to over 200,000 individuals, with an $\mathrm{N}_{\mathrm{e}}$ of approximately

$14540,000(>20 \%)[12,46,47]$. Cheetahs are estimated to number 6674 individuals with an $\mathrm{N}_{\mathrm{e}}$ of

146 between 1001-2937 (15-44\%) [48, 49]. Some re-introduced populations of European bison

147 (Bison bonasus) have $\mathrm{N}_{\mathrm{e}} / \mathrm{N}$ values as low as $0.05(5 \%)$ [50]. The island population of A. getulus,

148 therefore, has one of the smallest recorded effective population sizes relative to their census size. 
149 One caveat of our study was the sampling regime. The sampling density for mtDNA was low

150 although samples were collected from sites across the entire island of Fuerteventura, whereas

151 sampling density for nuclear DNA was higher but restricted to a single area. As such, we found

152 no evidence of population structure. However, there are no geographic barriers to dispersal

153 across the island, as squirrels have been observed in all regions [20, 21], thus population

154 structure may be absent altogether. Better coverage of the island or perhaps the collection of

155 whole genomes may provide further insight into this recent founding event.

156 We have shown that the A. getulus population on Fuerteventura has undergone an intense genetic

157 bottleneck during their colonization of the island. However, despite their lack of genetic diversity

158 and low effective population size, they have successfully established and spread across the

159 island, providing an ideal example of the founder effect.

161 Ethics. All sample collection followed the animal care protocols of the University of Manitoba

162 (Animal Care and Use Committee \#F14-032) and the government of Fuerteventura (Cabildo

163 Insular de Fuerteventura \#14885). Samples from Morocco were obtained with the permission of

164 the Ministry of Territory Development, Water and Environment of Morocco (512/0170 March

165 2006) and brought back to the EU under the authorization of the Government of the Canary

166 Islands.

167 Data accessibility. Data will be available at Dryad

168 Authors' contributions. JMW and ML-D discussed the idea and KVK, JMW and SDP designed

169 the study. KVK, AVDM, ML-D and JMW conducted the field work. KVK and AVDM

170 performed the lab work. KVK, CG, and SDP contributed to the analysis and interpretation of the

171 data. All authors contributed to the manuscript preparation and revisions. All authors approved 
172 the final version of the manuscript and agree to be held accountable for the content of this

173 publication.

174 Competing interests. The authors have no competing interests to declare.

175 Funding. This research was supported by a Natural Sciences and Engineering Research Council

176 of Canada Discovery grant and a University of Manitoba University Research Grant awarded to

177 JMW, and a University of Manitoba Faculty of Science Undergraduate Summer Research

178 Experience awarded to KVK. The Obra Social de La Caja de Canarias and the Ministry of

179 Education of the Spanish Government funded the expedition to Morocco and samples collected

180 in Fuerteventura in 2006. ML-D is funded by the Cabildo de Tenerife under the identification

181 mark “Tenerife 2030” (P. INNOVA 2016-2021).

182 Acknowledgements. We would like to acknowledge Lucy Johnson for indispensable assistance

183 and instruction in laboratory and analysis techniques.

184 References

185

186 1. Lande R. 1988 Genetics and demography in biological conservation. Science 16, 1455-1460.

$187 \quad$ (doi:10.1126/science.3420403)

188 2. Bijlsma R, Bundgaard J, Boerema AC. 2000 Does inbreeding affect the extinction risk of

189 small populations?: predictions from Drosophila. J. Evolution. Biol. 13, 502-514.

$190 \quad$ (doi:10.1046/j.1420-9101.2000.00177.x)

191 3. Charlesworth D, Willis JH. 2009 The genetics of inbreeding depression. Nat. Rev. Genet. 10,

192 783-796. (doi:10.1038/nrg2664)

193 4. Ouborg NJ, Pertoldi C, Loeschcke V, Bijlsma RK, Hedrick PW. 2010 Conservation genetics

194 in transition to conservation genomics. Trends Genet. 26, 177-187.

$195 \quad$ (doi:10.1016/j.tig.2010.01.001) 
5. Wright S. 1931 Evolution in Mendelian populations. Genetics 16, 97-159. (PMID:17246615)

197 6. Charlesworth B. 2009 Effective population size and patterns of molecular evolution and variation. Nat. Rev. Genet. 10, 195-205. (doi:10.1038/nrg2526)

199 7. Dlugosch KM, Parker IM. 2008 Founding events in species invasions: genetic variation, 200 adaptive evolution, and the role of multiple introductions. Mol. Ecol. 17: 431-449. (doi:10.1111/j.1365-294X.2007.03538.x)

8. Simberloff D. 2009 The role of propagule pressure in biological invasions. Annu. Rev. Ecol. Evol. S. 40, 81-102. (doi:10.1146/annurev.ecolsys.110308.120304)

9. Estoup A, Ravigné V, Hufbauer R, Vitalis R, Gautier M, Facon B. 2016 Is there a genetic paradox of biological invasion?. Annu. Rev. Ecol. Evol. Syst. 47, 51-72. (doi:10.1146/annurev-ecolsys-121415-032116)

207 10. Labonne J, Kaeuffer R, Gueraud F, Zhou M, Manicki A, Hendry AP. 2016 From the bare 208 minimum: genetics and selection in populations founded by only a few parents. Evol. Ecol. $209 \quad$ Res. 17, 21-34.

210 11. Signorile AL, Wang J, Lurz PWW, Bertolino S, Carbone C, Reuman DC. 2014 Do founder 211 size, genetic diversity and structure influence rates of expansion of North American grey 212 squirrels in Europe?. Divers. Distrib. 20, 918-930. (doi:10.1111/ddi.12222)

213 12. Abadía-Cardoso A, Freimer NB, Deiner K, Garza JC. 2017 Molecular population genetics of 214 the northern elephant seal Mirounga angustirostris. J. Hered. 108, 618-627.

$215 \quad$ (doi:10.1093/jhered/esx053)

216 13. Barson NJ, Cable J, van Oosterhout C. 2009 Population genetic analysis of microsatellite 217 variation of guppies (Poecilia reticulata) in Trinidad and Tobago: evidence for a dynamic 
source-sink metapopulation structure, founder events and population bottlenecks. $J$.

Evolution. Biol. 22, 485-497. (doi:10.1111/j.1420-9101.2008.01675.x)

14. Russell JC, Hobins JH, Fewster RM. 2019 Phylogeography of invasive rats in New Zealand.

$221 \quad$ Front. Ecol. Evol. 7, 48. (doi:10.3389/fevo.2019.00048)

222 15. Kolar CS, Lodge DM. 2001 Progress in invasion biology: predicting invaders. Trends Ecol.

$$
\text { Evol. 16, 199-204. (doi:10.1016/S0169-5347(01)02101-2) }
$$

16. Huchon D, Delsuc F, Catzeflis FM, Douzery EJP. 2002 Armadillos exhibit less genetic confirm a founder effect in Dasypus novemcinctus (Xenarthra). Mol. Ecol. 8, 1743-1748.

17. Gloag R, Ding G, Christie JR, Buchmann G, Beekman M, Oldroyd BP. 2016 An invasive social insect overcomes genetic load at the sex locus. Nat. Ecol. Evol. 1, 11. (doi:10.1038/s41559-016-0011)

231 18. Carson HL, Templeton AR. 1984 Genetic revolution in relation to speciation phenomena: the

232 founding of new populations. Ann. Rev. Ecol. Evol. S. 15, 97-131.

233 (doi:10.1146/annurev.es.15.110184.000525)

234 19. Machado, A. 1979. The introduction of the Getulian squirrel (Atlantoxerus getulus L., 1758)

235 in Fuerteventura, Canary Islands. Egypt. J Wild. Nat. Res. 2, $182-202$.

236 20. López-Darias M, Lobo JM. 2008 Factors affecting invasive species abundance: The Barbary 237 ground squirrel on Fuerteventura Island, Spain. Zool. Stud. 47, 268-281.

238 21. López-Darias M, Lobo JM, Gouat P. 2008 Predicting potential distributions of invasive 239 species: the exotic Barbary ground squirrel in the Canarian archipelago and the west 240 Mediterranean region. Biol. Invas. 10, 1027-1040. (doi:10.1007/s10530-007-9181-2) 
22. Haavie J, Sætre G-P, Moum T. 2000 Discrepancies in population differentiation at microsatellites, mitochondrial DNA and plumage colour in the pied flycatcher - inferring evolutionary processes. Mol. Ecol. 9, 1137-1148. (doi:10.1046/j.1365-294x.2000.00988.x)

23. Fisher-Reid MC, Wiens JJ. 2011 What are the consequences of combining nuclear and mitochondrial data for phylogenetic analysis? Lessons from Plethodon salamanders and 13 other vertebrate clades. BMC Evol. Biol. 11, 300. (doi:10.1186/1471-2148-11-300)

24. Schneider TC, Kappeler PM, Pozzi L. 2016 Genetic population structure and relatedness in the narrow-striped mongoose (Mungotictis decemlineata), a social Malagasy carnivore with sexual segregation. Ecol. Evol. 6, 3734-3749. (doi:10.1002/ece3.2123)

25. Wan Q, Wu H, Fujihara T, Fang S. 2004 Which genetic marker for which conservation genetics issue? Electrophoresis 25, 2165-2176. (doi:10.1002/elps.200305922)

26. Waterman JM. 1995 The social organization of the Cape ground squirrel (Xerus inauris; Rodentia: Sciuridae). Ethology 101, 130-147. (doi:10.1111/j.1439-0310.1995.tb00352.x)

27. López-Darias M, Ribas A, Feliu C. 2008 Helminth parasites in native and invasive mammal populations: comparative study on the Barbary ground squirrel Atlantoxerus getulus L. (Rodentia, Sciuridae) in Morocco and the Canary Islands. Acta Parasitol. 53, 296-301. (doi:10.2478/s11686-008-0036-5)

28. Piquet JC, López-Darias M, van der Marel A, Nogales M, Waterman J. 2018 Unraveling behavioral and pace-of-life syndromes in a reduced parasite and predation pressure context: personality and survival of the Barbary ground squirrel. Behav. Ecol. Sociobiol. 72, 147. (doi:10.1007/s00265-018-2549-8) 
29. van der Marel A, López-Darias M, Waterman JM. 2019 Group-enhanced predator detection and quality of vigilance in a social ground squirrel. Anim. Behav. 151, 43-52. (doi:10.1016/j.anbehav.2019.02.017)

30. Jombart T. 2007 adegenet: a R package for the multivariate analysis of genetic markers. Bioinformatics 24, 1403-1405. (doi:10.1093/bioinformatics/btn129)

31. Jombart T, Ahmed I. 2011 adegenet 1.3-1: new tools for the analysis of genome-wide SNP data. Bioinformatics 21, 3070-3071. (doi:10.1093/bioinformatics/btr521)

32. Paradis E. 2010 pegas: an R package for population genetics with an integrated-modular approach. Bioinformatics 26, 419-420. (doi:10.1093/bioinformatics/btp696)

33. R Core Team. 2018 R: A language and environment for statistical computing. R Foundation

272 for Statistical Computing, Vienna, Austria. (URL: https://www.R-project.org/)

273 34. Dray S, Dufour A. 2007 The ade4 package: implementing the duality diagram for ecologists. J. Stat. Softw. 22, 1-20. (doi:10.18637/jss.v022.i04)

275 35. Waples RS, Do C. 2008 LDNE: a program for estimating effective population size from data on linkage disequilibrium. Mol. Ecol. Resour. 8, 753-756. (doi:10.1111/j.1755-

278 36. van Oosterhout C, Hutchinson WF, Wills DPM, Shipley P. 2004 Micro-Checker: software 279 for identifying and correcting genotyping errors in microsatellite data. Mol. Ecol. Notes 4, 535-538. (doi:10.1111/j.1471-8286.2004.00684.x)

281 37. Dakin EE, Avise JC. 2004 Microsatellite null alleles in parentage analysis. Heredity 93, 504$282 \quad$ 509. (doi:10.1038/sj.hdy.6800545)

283 38. Chybicki IJ, Burczyk J. 2009 Simultaneous estimation of null alleles and inbreeding 284 coefficients. J. Hered. 100, 106-113. (doi:10.1093/jhered/esn088) 
39. Frankham R. 1995 Inbreeding and extinction: a threshold effect. Conserv. Biol. 9, 792-799. (doi:10.1046/j.1523-1739.1995.09040792.x)

40. Crnokrak P, Roff DA. 1999 Inbreeding depression in the wild. Heredity 83, 260-270.

$288 \quad$ (doi:10.1038/sj.hdy.6885530)

289 41. Blackburn TM, Lockwood JL, Cassey P. 2015 The influence of numbers on invasion success. Mol. Ecol. 24, 1942-1953. (doi:10.1111/mec.13075)

291 42. López-Darias M, Nogales M. 2008 Effects of the invasive Barbary ground squirrel (Atlantoxerus getulus) on seed dispersal systems of insular xeric environments. J. Arid

295 (Atlantoxerus getulus L.) en la isla de Fuerteventura; su introducción, su biología y su 296 impacto en el medio. Santa. Santa Cruz de Tenerife, Spain: Ministerio de Agricultura, Pesca 297 y Alimentación. Instituto Nacional para la Conservación de la Naturaleza.

298 44. van der Marel A. 2019 Life history traits, social organisation and the drivers of sociality in an 299 invasive ground squirrel. Doctoral dissertation, University of Manitoba, Winnipeg, MB.

300 45. Hedrick PW. 1994 Purging inbreeding depression and the probability of extinction: full-sib $301 \quad$ mating. Heredity 73, 363-372. (doi:10.1038/hdy.1994.183)

302 46. Slade RW, Moritz C, Hoelzel AR., Burton HR. 1998 Molecular population genetics of the 303 southern elephant seal Mirounga leonina. Genetics 149, 1945-1957. (PMID:9691049)

304 47. Hückstädt L. 2015 Mirounga angustirostris. The IUCN Red List of Threatened Species. 305 Version 2015. International Union for Conservation of Nature. Retrieved April 19, 2020. $306 \quad$ (doi:10.2305/IUCN.UK.2015-2.RLTS.T13581A45227116.en) 
48. Kelly MJ. 2001 Lineage loss in Serengeti cheetah: consequences of high reproductive variance and heritability of fitness on effective population size. Conserv. Biol. 15, 137-147. (doi:10.1111/j.1523-1739.2001.99033.x)

49. Durant S, Mitchell N, Ipavec A, Groom R. 2015 Acinonyx jubatus. The IUCN Red List of

311 Threatened Species. Version 2015. International Union for Conservation of Nature. Retrieved July 16, 2019. (doi:10.2305/IUCN.UK.2015-4.RLTS.T219A50649567.en)

313 50. Tokarska M, Pertoldi C, Kowalczyk R, Perzanowski K. 2011 Genetic status of the European 314 bison Bison bonasus after extinction in the wild and subsequent recovery. Mammal Rev. 41, 315 151-162. (doi:10.1111/j.1365-2907.2010.00178.x)

316 51. van der Marel A, Waterman JM, López-Darias M. 2020 Social organization in a North

317 African ground squirrel. J. Mamm., gyaa031. (doi:10.1093/jmammal/gyaa031)

318 52. Aulagnier S, Gouat P, Thévenot M. 2013 Atlantoxerus getulus Barbary ground squirrel, p.

319 43-44. In Mammals of Africa: Volume III, ed D C D Happold. London: Bloomsbury

320 Publishing.

321 53. Kumar S, Stecher G, Tamura K. 2015 MEGA7: Molecular Evolutionary Genetics Analysis

322 version 7.0. Mol. Biol. Evol. 33, 1870-1874. (doi:10.1093/molbev/msw054)

323 54. Detwiler JT, Zajac AM, Minchella DJ, Belden LK. 2012 Revealing cryptic parasite diversity 324 in a definitive host: Echinostomes in muskrats. J. Parasitol. 98, 1148-1155.

$325 \quad$ (doi:10.1645/GE-3117.1)

326 55. Manjerovic MB, Wood PB, Edwards JW. 2009 Mast and weather influences on population 327 trends of a species of concern: the Allegheny woodrat. Am. Midl. Nat. 162, 52-61.

$328 \quad$ (doi:10.1674/0003-0031-162.1.52) 
329 56. Pompanon F, Bonin A, Bellemain E, Taberlet P. 2005 Genotyping errors: causes,

$330 \quad$ consequences and solutions. Nat. Rev. Genet. 6, 847-846. (doi:10.1038/nrg1707)

331 57. Hillis DM, Moritz C, Mable BK. 1996 Nucleic Acids II: The Polymerase Chain Reaction, p.

332 238. In Molecular Systematics, 2nd ed. Sunderland: Sinauer Associates, Inc.

333 58. Stewart DT, Baker AJ. 1994 Patterns of sequence variation in the mitochondrial D-loop

334 region of shrews. Mol. Biol. Evol. 11, 9-21. (doi:10.1093/oxfordjournals.molbev.a040096) 


\section{$338 \quad$ Figures and Tables}

339 Figure 1. Evolutionary relationships between island (blue) and mainland (red) Atlantoxerus 340 getulus based on the mitochondrial DNA displacement loop. Relationships inferred using the 341 Neighbour-Joining method with 1000 bootstrap replicates. Evolutionary distances calculated 342 using the Tamura-Nei method. All codon positions were included (total 1027 positions). Made in 343 MEGA7 [53].

345 Figure 2. Average inbreeding coefficients of 256 Atlantoxerus getulus individuals based on 346 microsatellite markers of nuclear DNA. The $F$ values ranged from $0.097-0.596$ (mean $F=$ $3470.233)$. 
349 Table 1. Nucleotide differences within the mitochondrial d-loop of six Atlantoxerus getulus 350 haplotypes from Sidi Ifni, Morocco.

351

\begin{tabular}{|c|c|c|c|c|c|c|c|c|c|c|c|c|c|c|c|c|}
\hline Position & 27 & 95 & 98 & 111 & 114 & 173 & 252 & 258 & 276 & 282 & 289 & 299 & 316 & 746 & 824 & 970 \\
\hline M03 & C & A & C & $T$ & G & C & C & C & C & C & A & A & $T$ & A & $T$ & $T$ \\
\hline M06 & . & . & . & . & . & . & $T$ & . & . & . & . & . & . & G & . & . \\
\hline M10 & . & G & . & . & . & . & . & . & $T$ & . & G & G & . & . & C & . \\
\hline M18 & $T$ & . & . & C & . & . & . & . & . & . & . & . & C & . & C & C \\
\hline M19 & . & . & A & . & A & $T$ & . & . & . & . & . & . & . & . & C & . \\
\hline M21 & . & G & . & . & . & . & . & $T$ & . & . & . & . & C & . & C & . \\
\hline $\mathrm{FV}$ & . & . & . & . & . & . & . & . & . & $\mathbf{T}$ & . & G & . & . & C & . \\
\hline
\end{tabular}


bioRxiv preprint doi: https://doi.org/10.1101/2020.08.04.236695; this version posted August 5, 2020. The copyright holder for this preprint (which was not certified by peer review) is the author/funder, who has granted bioRxiv a license to display the preprint in perpetuity. It is made available under aCC-BY-ND 4.0 International license.

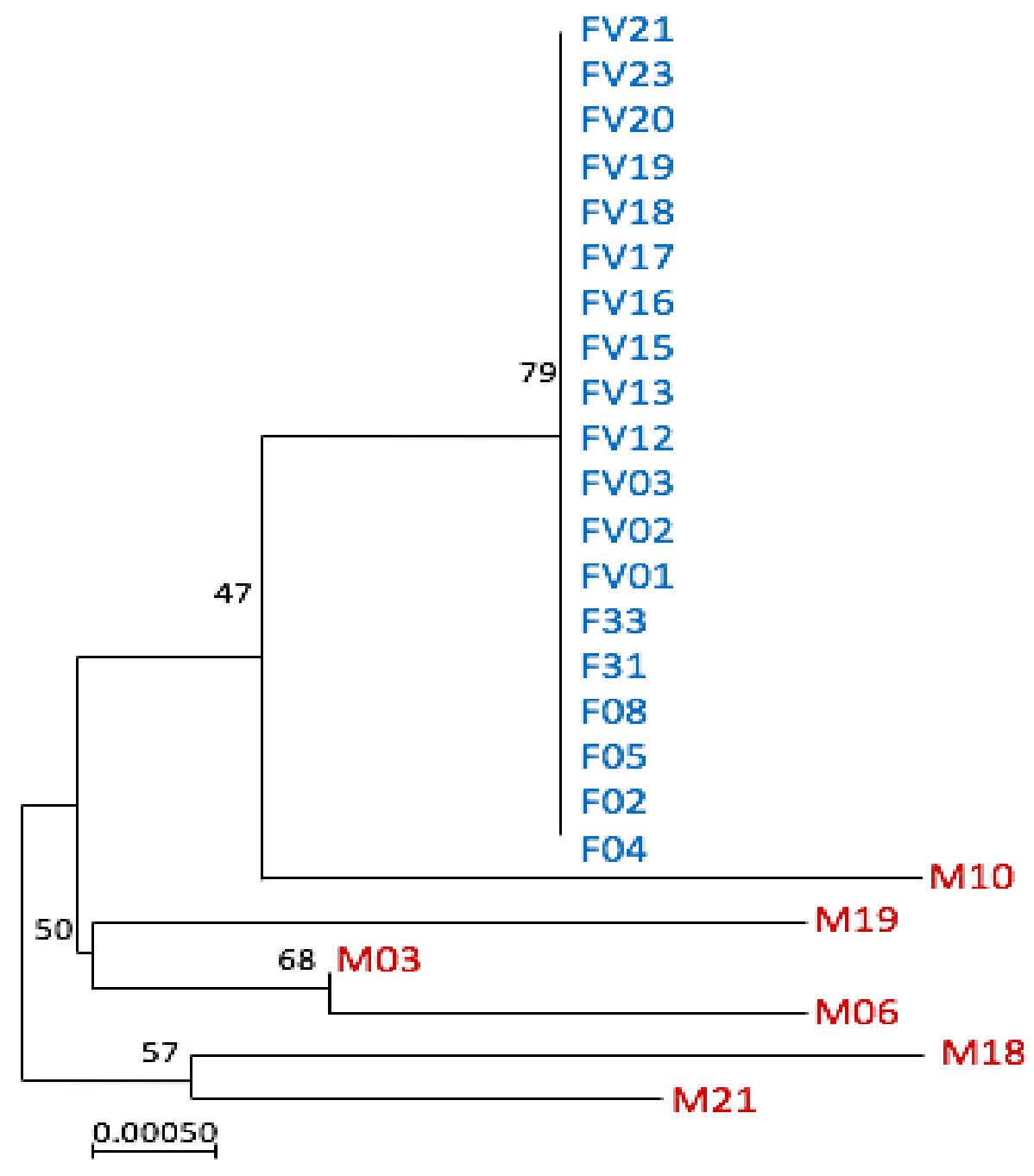

Figure 1. 


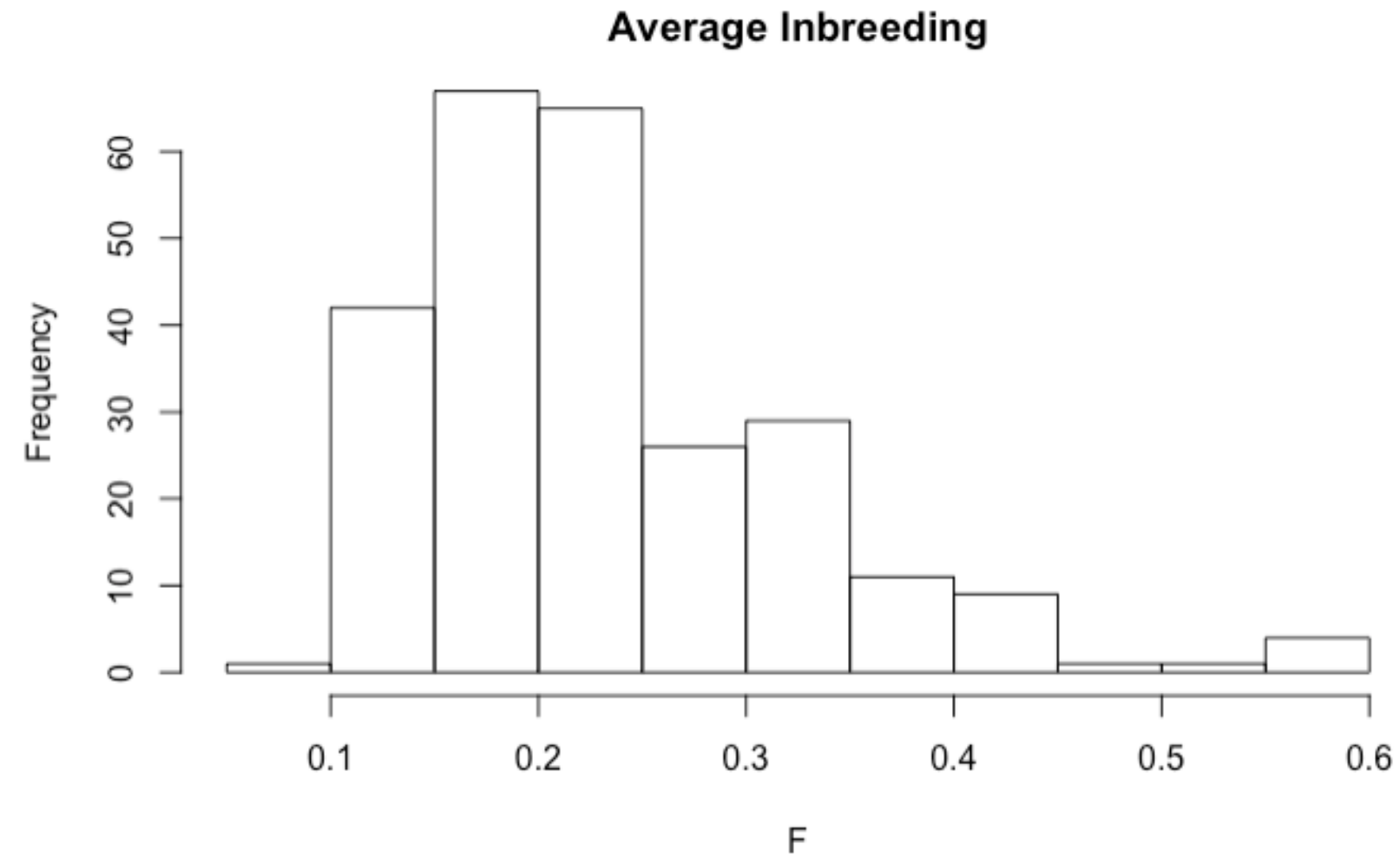

Figure 2.

361 